\title{
Levantamento de informações socioambientais na comunidade da praia de Macapá - Luís Correia - Piauí - Brasil: contribuições ao gerenciamento costeiro participativo
}

\author{
Socioenvironmental Information gathering in the communitie of Macapa beach- \\ Luis Corrêa-Piauí-Brazil: contributions to the participatory coastal management
}

Glairton Cardoso Rocha Doutor em Geografia, professor do Instituto Federal de Educação, Ciência e Tecnologia, Piauí, Brasil glairtongeo@ifpi.edu.br

Antonio Carlos Tavares Doutor em Geografia, professor adjunto do Instituto de Geociências e Ciências Exatas da UNESP, Campus de Rio Claro, Brasil atavares@rc.unesp.br

\begin{abstract}
Resumo
Os ambientes costeiros são considerados espaços estratégicos devido à diversidade de funções econômicas, sociais e ambientais. Nesses espaços se desenvolvem múltiplos usos, por agentes que possuem os mais variados interesses, levando muitas vezes a conflitos de ordem socioambiental. Estratégias de gestão podem ser usadas para enfrentar tais problemas, especialmente através do envolvimento popular. A inserção das comunidades deve ocorrer desde o levantamento de informações até o processo de tomada de decisão. O presente trabalho objetiva coletar informações socioambientais por meio do uso de questionários semi-estruturados, na comunidade de Macapá, município de Luis Correia, estado do Piauí. Os questionários foram aplicados nas residências da comunidade e respondidos por um representante familiar, perfazendo um total de 78 participantes. A partir das informações levantadas foi possível traçar o perfil socioeconômico da comunidade, avaliar a estrutura higiênico-sanitária e identificar potencialidades e limitações de uso. Assim, verificaramse o baixo nível de escolaridade e renda média das famílias e as deficiências relacionadas ao abastecimento de água, esgotamento sanitário e coleta de resíduos. Além disso, foi possível identificar potencialidades que podem ser exploradas por atividades de ecoturismo, por exemplo, e limitações relacionadas à implantação de estruturas rígidas. As informações apuradas são úteis para o delineamento de políticas de gestão que compatibilizem o desenvolvimento econômico, a melhoria na qualidade de vida da população e a manutenção da qualidade das funções ambientais.
\end{abstract}

Palavras-chave: gestão costeira, políticas públicas, potencialidades e limitações de uso.

\begin{abstract}
Costal environments are considered strategic spaces due to the diversity of economic, social and environmental functions. Agents that have the most varied interests develop several uses in those spaces, many times leading to socioenvironmental conflicts. Management strategies can be used to face such problems, particularly through popular engagement. The inclusion of communities should happen since the information gathering to the process of decision taking. The present issue aims to collect socioenvironmental information with semi-structured questionnaires in the communitie of Macapá, in the city of Luis Corrêa, State of Piauí. The questionnaires were applied in the cities residences, answered by a family's representative, making up 63 attendees. From the information gathered, it was possible to draw the socioeconomic profile of the community, to evaluate the hygienic and sanitary structure and identify potentialities and limitations of use. Thus, a low level of schooling and average income of families were verified, deficiencies in relation to water supply, sanitary sewage
\end{abstract}


and waste collection. Besides that, it was possible to identify potentialities that can be explored by ecotourism activities, for instance, besides the limitations related the implantation of rigid structures. The collected information are useful for the drawing of management policies that reconcile the economic development, the improvement of the life quality of the population and the quality keeping of the environmental functions.

Keywords: coastal management, public policies, potentialities and limitation of use.

\section{INTRODUÇÃO}

As zonas costeiras são consideradas áreas de alta vulnerabilidade ambiental, em especial por conta da intensa instabilidade morfossedimentar, devido à dinâmica ambiental acentuada, resultado da interação dialética de diversos agentes (atmosféricos, oceanográficos, continentais e humanos) que realizam rápidas modificações (ROCHA, 2016; AB'SABER, 2000). Isso, somado ao contingente populacional significativo, torna necessário o desenvolvimento e aperfeiçoamento dos modelos de gestão, tanto do ponto de vista territorial, quanto ambiental.

Para o Plano Nacional de Gerenciamento Costeiro (PNGC), o gerenciamento costeiro pode ser entendido como "um conjunto de atividades e procedimentos que, por meio de instrumentos específicos, permite a gestão da utilização dos recursos da zona costeira" (BRASIL, 1997, p.4). Estes instrumentos devem se embasar no conhecimento técnico-científico, com o intuito de disciplinar o uso e a ocupação do solo e se adequar às especificidades do lugar.

Os instrumentos de gestão voltados para as zonas costeiras devem considerar o papel estratégico que esse recorte espacial assume em todo o planeta, como econômico, por exemplo, considerando os múltiplos recursos e usos atualmente desenvolvidos nesse fragmento territorial, além de seu potencial para usos futuros, pois eles possuem uma importância bastante significativa, como ambiente de amortecimento energético da ação das ondas, dotados de condição excepcional para se ajustar às mudanças do nível do mar (MUEHE, 2001), e por serem habitat de vasta biota de flora e fauna, como os manguezais e manchas residuais de mata atlântica.

Alem disso, muitos desses fragmentos espaciais abrigam comunidades humanas que desenvolvem atividades de subsistência, como a agricultura familiar e a pequena pesca, e dependem diretamente dos recursos naturais costeiros, como a praia de Macapá no litoral piauiense. Para Moraes (2007), essas comunidades estão sujeitas ao desaparecimento caso não sejam contempladas com ações de proteção.

A costa piauiense apresenta uma extensão de $66 \mathrm{Km}$, tendo como limites naturais: a leste o rio Ubatuba, que separa o Piauí do estado do Ceará; a oeste o rio Parnaíba, que limita o Piauí com o estado do Maranhão; ao norte o Oceano Atlântico; ao sul os municípios de Parnaíba, Bom Princípio do Piauí e Cocal. Ela possui um grande potencial voltado para o desenvolvimento do turismo dada a 
beleza cênica e paisagística presente em toda sua planície litorânea, dotada de uma diversidade e complexidade considerável de formas como os estuários, campos de dunas, lagoas, deltas, arenitos de praia, barras arenosas, planícies de maré e as praias arenosas.

Apesar de ainda conservar trechos relativamente preservados e pouco modificados pela ação humana, já se identificam no Piauí algumas ações que podem acarretar problemas, como a construção do porto de Luís Correia e a implantação de estruturas urbanas rígidas, além da urbanização da Praia de Atalaia. Outras praias do estado também já apresentam problemas de ordem socioambiental, necessitando de planos de intervenção que possam compatibilizar as características dinâmicas dos sistemas costeiros com os usos.

A praia de Macapá pertence à Área de Proteção Ambiental do Delta do Rio Parnaíba. Esta APA é uma unidade de conservação administrada pelo IBAMA, criada por decreto em 1996, visando proteger o ecossistema costeiro formado por mangues e dunas localizados nos estados do Maranhão, Piauí e Ceará. Situada na zona equatorial, com maior extensão nos sentidos dos paralelos, abrange a parte mais setentrional do Estado do Piauí.

Nesta praia está assentado o povoado de Macapá, formado por uma comunidade tradicional de pescadores litorâneos e localizado a $2^{\circ} 53^{\prime}$ latitude sul e $41^{\circ} 26^{\prime}$ longitude oeste, no município de Luís Correia, estado do Piauí, região Nordeste do Brasil.

À luz dessas discussões, propõe-se como objetivo geral dessa pesquisa traçar o perfil socioeconômico da população residente na praia de Macapá (Litoral leste de Luís Correia - PI), além de avaliar os equipamentos de infraestrutura e identificar potencialidades e limitações de uso. Ressalta-se que tais informações são relevantes para o ordenamento das atividades socioeconômicas e o desenvolvimento de planos de gestão para as zonas costeiras.

\section{METODOLOGIA}

O uso de variáveis socioambientais tem sido uma ferramenta usada com bastante êxito nas ciências humanas, mas também possui uma aceitação crescente nas ciências da terra, sobretudo nos trabalhos que enfocam o meio ambiente de maneira geral. Um dos procedimentos mais utilizados para a coleta de tais informações é a aplicação de questionários, especialmente em trabalhos que objetivam inferir valores e atitudes ambientais ou o significado e a história dos lugares.

Tal procedimento vem sendo utilizado com grande êxito científico, como, por exemplo, no Reino Unido (ERGIN, et al., 2004; TUDOR; WILLIAMS, 2006; MORGAN, 1999) e no Brasil (TAVARES et al., 1993, SANTOS, et al., 2005; PEREIRA; CANDELLA; CARVALHO, 2003; MARCELINO, 2005; LESSA; POLETTE, 2007; STORI, 2007; ROCHA; DINIZ, 2011; ROCHA; DINIZ, 2014; ROCHA 2015). 
As informações socioambientais baseiam-se no fato de que há uma relação de interdependência entre a natureza e o homem. Por isso assumem um caráter interdisciplinar (MENDONÇA, 2001) e são de grande importância para o delineamento de políticas públicas e a elaboração de planos de gestão participativos, como no caso relatado por Stori (2007) sobre gestão compartilhada na Reserva Extrativista do Corumbaú, no estado da Bahia. Os valores e significados ambientais devem ser identificados e contemplados nos planos gestores (MATOS, 2010).

Para a coleta de dados socioeconômicos, aplicaram-se questionários semiestruturados com 32 questões relacionadas às características dos entrevistados, como sexo, idade, naturalidade, renda familiar, escolaridade, condições higiênico-sanitárias do lugar, além de perguntas sobre a qualidade dos equipamentos de infraestrutura, riscos associados ao banho de mar e as principais transformações da paisagem nas últimas quatro décadas. Os dados coletados visaram identificar, na perspectiva do público, as potencialidades e limitações de uso dos recursos naturais da praia, além de avaliar os equipamentos de infraestrutura e observar problemas de ordem social e ambiental.

Foram aplicados 78 questionários, um em cada residência da comunidade de Macapá, procurando, sempre que possível, que ele fosse respondido pelo morador de maior idade. O período de coleta compreende os meses de maio e junho de 2012.

Para a caracterização socioeconômica foram considerados apenas os questionários respondidos por indivíduos residentes, permanentemente, na praia de Macapá. Para isso foram descartados 15 questionários e usados os dados dos 63 questionários restantes para tratar, estritamente, de informações sociais e econômicas da população local, como escolaridade e renda. Para as demais questões como, por exemplo, transformações da paisagem e observações das potencialidades e limitações de uso, foram consideradas as informações de todos os questionários $\operatorname{amostrados}(\mathrm{n}=78)$.

\section{RESULTADOS E DISCUSSÕES}

\subsection{Caracterização socioeconômica da comunidade}

Entre os entrevistados desse grupo, 57,1\% eram mulheres e 42,9\% homens. Este resultado é consequência, em geral, de estruturas familiares mais tradicionais, nas quais a mulher é responsável pelos cuidados com o lar. Sendo assim, foi o público encontrado com mais frequência nas residências durante o dia e, por isso, formou um grupo maior, apesar de não se configurar uma diferença tão significativa.

Os indivíduos foram classificados, de acordo com a idade, em quatro grupos: com idades entre 15 e 20 anos, entre 21 e 30 anos, entre 31 e 40 anos, e acima de 40 anos de idade. A maior parte dos entrevistados tinha de 31 a 40 anos, representando 33,3\%, seguida dos indivíduos com idade superior 
a 40 anos, com 28,6\%. As pessoas com idade entre 15 e 20 anos constituíram 23,8\% dos entrevistados e o grupo com idade entre 21 e 30 anos, 14,3\%. A maior presença de entrevistados pertencentes às maiores faixas etárias é resultado da opção metodológica, na qual se priorizou os indivíduos mais velhos, devido à probabilidade dos mesmos terem uma maior vivência na área de estudos e presenciado uma maior gama de modificações paisagísticas.

Além disso, é possível que estes indivíduos possuam, de forma mais forte, relações afetivas com o lugar, atribuindo, assim, significados diferentes aos elementos da paisagem, como observou Tavares et al., (1993), na Represa dos Sonhos, em Monte Aprazível, estado de São Paulo, onde os atores sociais com maior idade e com maior vivência na área de estudos desenvolveram uma relação sentimental mais intensa com a represa. Esta relação sentimental do homem com o lugar denominase topofilia (TUAN, 1980).

Em relação à renda, a maior parte da população $(85,7 \%)$ declarou possuir renda de até um salário mínimo. Isto se deve à participação desses atores sociais no setor informal da economia, com alta dependência de atividades econômicas tradicionais e do comércio de gêneros de baixo valor agregado, como o pescado e alguns produtos agrícolas. Outro fator que deve ser considerado como elucidativo para esse resultado é a baixa oferta de empregos formais. Outros 12,6\% informaram que possuem renda de um a três salários mínimos e 1,7\% dos entrevistados não informaram a renda.

Observou-se um baixo grau de escolaridade entre os entrevistados, pois a maior parte deles possui ensino fundamental incompleto, perfazendo o percentual de 52,4\%. Apenas 6,3\% dos residentes permanentes que participaram da pesquisa concluíram o ensino médio e somente uma pessoa teve acesso ao ensino superior. A baixa escolarização dos entrevistados também deve ser considerada como fator explicativo da distribuição dos entrevistados por renda, comentada anteriormente.

Constatou-se ainda que os indivíduos pertencentes às maiores faixas etárias tinham um menor grau de instrução, como mostra a tabela 1, que ilustra a distribuição dos partícipes da pesquisa em relação ao gênero, faixa etária e escolaridade.

Não se observou diferença de escolaridade entre os gêneros. Os baixos níveis de escolaridade e renda conferem aos populares alta vulnerabilidade socioeconômica. Kowarick (2003) afirma que essa vulnerabilidade diz respeito aos indivíduos que estão à margem dos processos sociais essenciais. Diegues (1996) alertou para o fato de que essas comunidades locais são muito mais suscetíveis a manobras econômicas, especialmente de desapropriação de suas moradias. $\mathrm{O}$ autor ressalta que a inclusão de tais atores sociais nos planos de gestão compartilhados visa a mitigar os conflitos de uso locais, obtendo resultados mais satisfatórios nas ações de gerenciamento.

Além disso, o baixo nível de escolaridade e a falta de especialização profissional comprometem a empregabilidade dos populares, fazendo necessárias ações de fomento às atividades 
econômicas tradicionalmente desenvolvidas na área, bem como ações voltadas ao estímulo da educação básica e profissional.

Tabela 1 - Distribuição dos entrevistados segundo faixa etária, gênero e escolaridade.

\begin{tabular}{|c|c|c|c|c|c|c|c|c|}
\cline { 2 - 10 } & \multicolumn{6}{c|}{ DISTRIBUIÇAO POR FAIXA ETARIA E GENERO } \\
\cline { 2 - 10 } & \multicolumn{1}{c}{$15-20$ anos } & \multicolumn{2}{c|}{$21-30$ anos } & \multicolumn{2}{c|}{$31-40$ anos } & \multicolumn{2}{c|}{$\begin{array}{c}\text { Maior de 40 } \\
\text { anos }\end{array}$} \\
\hline ESCOLARIDADE & $\mathrm{M}$ & $\mathrm{F}$ & $\mathrm{M}$ & $\mathrm{F}$ & $\mathrm{M}$ & $\mathrm{F}$ & $\mathrm{M}$ & $\mathrm{F}$ \\
\hline Näo Estudou & - & -- & -- & -- & 1 & 2 & 3 & 2 \\
\hline $\begin{array}{c}\text { Fundamental } \\
\text { incompleto }\end{array}$ & 3 & 3 & 3 & 2 & 4 & 7 & 3 & 8 \\
\hline $\begin{array}{c}\text { Fundamental } \\
\text { completo }\end{array}$ & 1 & 1 & 1 & -- & 2 & 2 & -- & -- \\
\hline Medio Incompleto & 1 & 5 & & 1 & 1 & 1 & 1 & -- \\
\hline Médio Completo & 1 & & 1 & 1 & - & - & -- & 1 \\
\hline $\begin{array}{c}\text { Superior } \\
\text { Incompleto }\end{array}$ & - & -- & -- & -- & 1 & - & -- & -- \\
\hline Superior Completo & - & -- & -- & -- & - & - & -- & -- \\
\hline TOTAIS & 6 & 9 & 5 & 4 & 9 & 12 & 7 & 11 \\
\hline
\end{tabular}

Fonte: Organizado por Rocha, G. C.

Dados coletados em campanhas de campo, entre maio e junho de 2012.

\subsection{Avaliação da estrutura higiênico-sanitária}

Para a avaliação da infraestrutura higiênico-sanitária da comunidade de Macapá, procurou-se observar três indicadores básicos: esgotamento sanitário, a origem da água usada para o abastecimento humano, a coleta e o destino final dos resíduos sólidos.

O local é totalmente desprovido de infraestrutura no que se refere ao esgotamento sanitário, habitualmente realizado por meio de fossas, que recebem $74,6 \%$ dos dejetos do público residente que participou da pesquisa. Outros 23,8\% afirmaram que lançam o esgoto a céu aberto e 1,6\% o lança diretamente no mar. Devido à falta de infraestrutura, os populares qualificaram o saneamento da área como péssimo, em uma escala com cinco opções: péssimo, ruim, regular, bom e ótimo.

Em relação à origem da água usada para abastecimento humano, observou-se, de maneira geral, que é oriunda de poços, sendo essa a resposta de 95,3\% dos entrevistados, enquanto apenas 4,7\% afirmaram comprar água potável para o consumo.

A coleta e disposição final dos resíduos sólidos se mostrou também uma questão problemática. Segundo as respostas, a coleta ocorre de forma irregular e esporádica. Assim, 30,7\% dos entrevistados qualificaram o serviço como péssimo; 20,5\% das pessoas o consideraram ruim; $23 \%$ regular; $19,2 \%$ de boa qualidade; e 3,8\%, ótimo. Duas pessoas não opinaram, correspondendo a $2,5 \%$ da amostra.

Outra questão abordou a disponibilidade de lixeiras públicas na praia. Foi perguntado aos usuários se eles consideravam satisfatória a quantidade das mesmas no local. 75,7\% dos entrevistados consideraram insatisfatória a quantidade de lixeiras disponibilizadas para o público visitante. Nas 
atividades de campo não foram visualizadas lixeiras à disposição dos frequentadores, nem mesmo pelas barracas de praia. No entanto, $24,3 \%$ consideraram a quantidade satisfatória, o que revela uma resposta contraditória em relação à realidade local.

Como a coleta de resíduos sólidos é realizada de maneira esporádica e irregular, há uma diversidade de ações associadas à destinação final dos materiais descartados. Dessa forma, 23 pessoas informaram que os resíduos domésticos são enterrados, 17 disseram que queimam seus resíduos e outras 15 declararam que os destinam às lixeiras públicas. Apenas duas (2) pessoas afirmaram que seus resíduos são coletados. Um (1) entrevistado afirmou descartar seus resíduos diretamente na praia. Outras respostas menos frequentes fizeram referência ao descarte de resíduos a céu aberto, em terrenos baldios, no lixão, no mar e na rua. A quantificação das respostas referentes ao destino dos resíduos pode ser observada na tabela 2.

Tabela 2 - Destino dos resíduos sólidos dos entrevistados

\begin{tabular}{c|c}
\hline \hline Destino dos Resíduos Sólidos & Quantidade \\
\hline Enterram & 23 \\
\hline Queimam & 17 \\
\hline Em lixeiras públicas & 15 \\
\hline Coletado & 2 \\
\hline Na Praia & 1 \\
\hline A céu aberto & 1 \\
\hline Em terrenos Baldios & 1 \\
\hline Lixão & 1 \\
\hline Mar & 1 \\
\hline Na rua & 1 \\
\hline Total & $\mathbf{6 3}$ \\
\hline \hline
\end{tabular}

Fonte: Organizado por Rocha, G. C.

Dados coletados em campanhas de campo, entre maio e junho de 2012.

Os dados mencionados revelam uma realidade preocupante, pois a falta de infraestrutura sanitária apresenta um alto risco de contaminação das águas superficiais e subsuperficiais usadas para o abastecimento humano, principalmente por conta da alta permeabilidade e porosidade que marca a geologia da planície litorânea, como asseverou Rocha (2015).

A contaminação dos aquíferos pode ter sérios desdobramentos para a saúde da comunidade local, por conta das doenças de veiculação hídrica, devido à larga utilização de poços para a obtenção de água para o abastecimento humano. Tal conjuntura eleva a preocupação em relação à coleta, tratamento e destino final dos resíduos ali produzidos, no intuito de evitar a contaminação das águas subterrâneas e, consequentemente, a proliferação de doenças, conforme mencionou Cavalcanti (2000). 
Os resultados referentes às condições higiênico-sanitárias da comunidade de Macapá são relativamente comuns em pequenas comunidades costeiras. Um exemplo disto é a praia da Caponga, no litoral leste do estado do Ceará. Esta praia, descrita por Rocha (2014), possui índices de urbanização e alteração da paisagem mais significativos do que os da área de estudo em questão.

\subsection{Potencialidades e limitações de uso na perspectiva dos usuários}

Os espaços litorâneos são espaços privilegiados, geograficamente, por conta de sua localização e dos recursos naturais disponíveis, entre eles a beleza cênica (natural), que é muito apreciada pelas sociedades contemporâneas e usada para fins de lazer, turismo e veraneio. A valorização de tais atributos físico-naturais pode ser observada também em algumas políticas públicas como, por exemplo, a criação de parques e reservas naturais, com o objetivo de preservação dos atributos ecológicos (DIEGUES, 1996), prática que teve início nos Estados Unidos, em 1872, com a criação do Parque Nacional de Yellowstone.

O conhecimento das vocações naturais e o reconhecimento das limitações de uso dos lugares são premissas fundamentais ao planejamento ambiental. Cavalcanti (2000) verificou nas comunidades locais do litoral piauiense um relativo conhecimento das potencialidades ambientais. Dessa forma, procurou-se identificar as principais potencialidades da praia de Macapá, na perspectiva dos usuários - nativos e visitantes - através de duas questões. A primeira se refere ao principal atrativo para a visitação do lugar e a segunda sobre a principal vocação da praia para o desenvolvimento de atividades econômicas.

Em relação aos atrativos à visitação relacionados pelos entrevistados, que foram verificados por uma questão aberta, sem respostas pré-definidas, um percentual de 30,7\% afirmaram que a beleza cênica e paisagística do lugar é a principal atração, sendo a resposta mais frequente. A totalidade dos entrevistados considera esse critério como importante elemento de valoração ambiental das praias, que, segundo Moraes (2007), é o ato de atribuir valor qualitativo ou quantitativo a um bem. Todos os entrevistados também afirmaram que a praia de Macapá é uma praia que dispõe de tal atributo, ou seja, é considerada uma praia bonita. Outras respostas que podem ser incluídas no grupo da beleza paisagística são: a paisagem do mangue, mencionada por duas pessoas, a paisagem do rio e a conservação ambiental, mencionadas por um (1) entrevistado.

A tranquilidade do lugar foi citada por $28,2 \%$ dos participes. A localização é um dos motivos que justificam essa tranquilidade, visto que a praia está localizada no extremo leste do município de Luis Correia, sendo a porção do litoral da cidade mais distante dos principais adensamentos populacionais. Ainda assim, o fluxo de pessoas nos períodos de alta estação é bastante considerável. 
O banho de mar e o mar calmo também foram mencionados de forma significativa, por 8,9\% das mesmas.

Outros fatores também foram mencionados em menor proporção pelos entrevistados, como, por exemplo, a segurança, a hospitalidade da comunidade local, a atividade pesqueira, as piscinas naturais, a segurança, o lazer e o turismo. Dois (2) dos entrevistados não opinaram.

Tabela 3 - Relação entre procedência e atrativos à visitação.

\begin{tabular}{|c|c|c|}
\hline PROCEDÊNCIA & ATRATIVOS A VISITAÇÃO & $\%$ \\
\hline \multirow{17}{*}{ NATIVO } & A praia & 3,17 \\
\hline & Banho de mar & 4,76 \\
\hline & Beleza & 30,15 \\
\hline & Conservação ambiental & 1,58 \\
\hline & Hospitalidade & 1,58 \\
\hline & Lazer & 4,76 \\
\hline & Mar calmo & 6,34 \\
\hline & Não opinaram & 1,58 \\
\hline & $\mathrm{O}$ mar & 4,76 \\
\hline & Paisagem do mangue & 3,17 \\
\hline & Pesca & 3,17 \\
\hline & Piscinas naturais & 1,58 \\
\hline & Receptividade & 1,58 \\
\hline & Segurança & 1,58 \\
\hline & Tranquilidade & 28,66 \\
\hline & Turismo & 1,58 \\
\hline & & Total 100 \\
\hline \multirow{7}{*}{ VISITANTE } & Beleza & 33,33 \\
\hline & Hospitalidade & 6,66 \\
\hline & Lazer & 6,66 \\
\hline & Não opinaram & 6,66 \\
\hline & $\mathrm{O}$ mar & 13,33 \\
\hline & Paisagem do mangue & 6,66 \\
\hline & Tranquilidade & 26,7 \\
\hline Total & & Total 100 \\
\hline
\end{tabular}

Fonte: Organizado por Rocha, G. C.

Dados coletados em campanhas de campo, entre maio e junho de 2012. 
A beleza cênica é relacionada por todos os grupos de escolaridade, sendo a resposta mais frequente entre os que não estudaram e aqueles com ensino fundamental completo, fundamental incompleto e com ensino superior incompleto. A tranquilidade do lugar também é mencionada por todos os grupos de escolaridade, excetuando-se os com ensino superior incompleto.

Ao relacionar as respostas dos entrevistados sobre os atrativos à visitação e sua procedência, observa-se que tanto os nativos quanto os visitantes mencionam a beleza cênica e a tranquilidade como atração à visitação do lugar, como se pode observar na tabela seguinte.

Outro questionamento foi realizado em relação à segurança do banho de mar. Dessa forma, $50 \%$ dos entrevistados qualificaram o banho de mar como sendo uma atividade segura, 10,2\% como muito segura, 19,3\% como moderadamente seguro e 20,5\% como perigoso. Vale ressaltar que ninguém qualificou a atividade como muito perigosa. A sensação de segurança quanto à atividade de banho se deve ao largo estirâncio apresentado pela praia, que favorece a dissipação da energia proveniente da arrebentação de ondas, e aos bancos arenosos dispostos paralelamente à face de praia, que também auxiliam no processo de amortecimento energético.

Apesar dessas características, a praia apresenta alguns riscos à prática do banho de mar, que podem passar despercebidos por um banhista mais desatento. Dentre eles, uma corrente de maré no sentido do curso fluvial durante as marés de enchente e no sentido do oceano durante as marés de vazante. Outro fator de risco se dá quando o banhista se afasta da praia durante as baixa-mares, pois o mesmo pode não perceber a maré enchendo e ter dificuldade para regressar.

Dessa forma, algumas medidas já foram tomadas, como a instalação de placas de sinalização de risco, bem como a presença de guardas salva-vidas do corpo de bombeiros, nos períodos de altaestação.

Ainda sobre o banho de mar, questionou-se sobre a frequência com que ele era praticado. Dessa forma, 33,3\% dos entrevistados afirmaram tomar banho de mar sempre que vão à praia; $57,7 \%$ o fazem de forma esporádica; e apenas $9 \%$ dos entrevistados nunca praticaram tal atividade.

No que se refere às potencialidades de uso, procurou-se identificar as principais atividades produtivas que podem ser desenvolvidas na praia de Macapá, sem que seus recursos naturais sejam comprometidos. Para isso, perguntou-se aos entrevistados qual seria a principal vocação da praia. A questão possuía cinco respostas estabelecidas previamente e um campo aberto com a opção "outro", na qual se poderia sugerir uma atividade não relacionada no questionário.

A atividade turística foi relacionada por $50 \%$ dos entrevistados, seguida da pesca controlada, com $24,5 \%$ das respostas. O lazer e o veraneio foram mencionados por 17,9\% dos participantes. Observa-se que a atividade turística, o lazer e o veraneio mencionados na pesquisa estão, de certo modo, ligados à potencialidade paisagística da área de estudos. 
O turismo local é extremamente dependente do público que se desloca das cidades circunvizinhas e da capital estadual, nos feriados prolongados e nos meses de julho e dezembro, períodos considerados como alta estação. O lugar não dispõe de rede hoteleira ou restaurantes sofisticados. Para Moraes (2007), uma das particularidades do litoral na modernidade é sua identificação como espaço de lazer por excelência, e lembra ainda que há uma maior valorização dos espaços preservados.

A pesca controlada foi mencionada pelo público entrevistado como a segunda maior potencialidade da área. Isso se explica pelo fato do povoado ser constituído basicamente por pessoas que praticam a pequena pesca e comercializam o pescado. Neste caso é necessário atentar para a capacidade e o período reprodutivo das espécies, permitindo sua recuperação populacional. $\mathrm{O}$ comércio foi lembrado apenas por $2,5 \%$ das pessoas, enquanto $5,1 \%$ não opinaram.

Cavalcanti (2000) ressalta que as principais potencialidades da planície costeira do estado do Piauí são as três atividades mencionadas pelo público (pesca, lazer e turismo), o que ratifica o conhecimento dos entrevistados sobre as potencialidades de uso da praia.

Ao relacionar a procedência do público entrevistado com as potencialidades de uso, observase que o turismo continua sendo a principal atividade mencionada pelos nativos e visitantes. No entanto, a atividade pesqueira perde importância para o público visitante, deixando de ser a segunda resposta mais frequente e passando a ser a terceira. A pesca foi mencionada por apenas $6,68 \%$ dos visitantes, como se vê na tabela 4.

Tabela 4 - Relação entre procedência e potencialidades de uso

\begin{tabular}{c|c|c}
\hline \multirow{2}{*}{ PROCEDÊNCIA } & POTENCIALIDADE & $\%$ \\
\hline \multirow{2}{*}{ NATIVO } & Turismo & 52,38 \\
\cline { 2 - 3 } & Pesca controlada & 26,98 \\
\cline { 2 - 3 } & Lazer e veraneio & 15,87 \\
\cline { 2 - 3 } & Comércio & 4,77 \\
\hline \multirow{4}{*}{ VISITANTE } & Turismo & 40 \\
\cline { 2 - 3 } & Lazer e veraneio & 26,66 \\
\cline { 2 - 3 } & Pesca controlada & 6,68 \\
\cline { 2 - 3 } & Não opinaram & 26,66 \\
\hline \multirow{2}{*}{ TOTAL } & & Total 100 \\
\hline
\end{tabular}

Fonte: Organizado por Rocha, G. C.

Dados coletados em campanhas de campo, entre maio e junho de 2012. 
Em relação às limitações de uso, procurou-se identificar, segundo as observações dos entrevistados, quais as atividades que apresentavam maior incompatibilidade com a dinâmica natural local. Como resposta majoritária foi mencionada a existência de loteamentos e construções próximos à linha de costa, citada por $48,7 \%$ das pessoas. Essa atividade fixa os sedimentos da parte dinâmica da praia, eliminando uma de suas características naturais, que é a de amortecimento energético, impedindo a sua adequação às condições excepcionais de ondas.

As atividades agroextrativistas desenvolvidas às margens dos rios aparecem como segunda resposta mais frequente, sendo citadas por $42,3 \%$ dos entrevistados. A retirada da vegetação nativa e o desenvolvimento de culturas às margens dos Rios Cardoso e Camurupim têm contribuído sensivelmente para o processo de assoreamento dos canais destes rios.

Os esportes aquáticos foram classificados como prejudiciais à pesca, segundo um (1) entrevistado (1,2\%). Seis (6) pessoas não opinaram, correspondendo a 7,7\% do público participante da pesquisa.

Além dos impactos ambientais decorrentes das atividades agrícolas nos ambientes costeiros, Cavalcanti (2000) lembra que as condições naturais, especialmente as características dos solos da planície costeira, como sua salinidade considerável, são desfavoráveis às práticas agrícolas.

Os entrevistados com maior escolaridade, a partir do curso médio incompleto, deram maior importância à implantação de estruturas rígidas próximas ao mar como principal atividade danosa ao ambiente.

Analisando-se as respostas referentes às atividades impactantes em relação à procedência do público entrevistado, observa-se que, para o visitante, o processo de ocupação é a atividade potencialmente mais danosa desenvolvida na área, como se pode observar na tabela 5. Ressalta-se que $20,01 \%$ dos visitantes não opinaram.

Em geral, as praias, quando submetidas à fixação pela ocupação, perdem, junto com a mobilidade dos sedimentos, a capacidade de ajustamento às condições de ondas e marés, tornandose mais vulneráveis aos efeitos das tempestades (marés de sizígia aliadas às condições de ondas excepcionais). Frequentemente, esse quadro leva os ambientes costeiros a uma série de problemas em decorrência de processos erosivos e, invariavelmente, prejuízos econômicos de grande monta (ROCHA, 2016).

A vulnerabilidade acentuada à erosão marinha, aliada ao aumento de residências, que também foi mencionado pelos entrevistados, torna-se preocupante, apesar da área ainda não se apresentar como orla de urbanização consolidada. Dessa forma, faz-se necessário o desenvolvimento de ações por parte do poder público, direcionadas ao disciplinamento do uso e ocupação do solo na referida praia, especialmente por conta do recuo da linha de costa informado pelos populares, relatado em trabalhos acadêmicos e constatado nesta pesquisa. 
Tabela 5 - Relação entre procedência e a percepção de atividades potencialmente danosas

\begin{tabular}{|c|c|c|}
\hline PROCEDÊNCIA & LIMITAÇÕES & $\%$ \\
\hline \multirow{5}{*}{ NATIVO } & $\begin{array}{l}\text { Atividades agroextrativistas próximas } \\
\text { aos rios }\end{array}$ & 46,03 \\
\hline & $\begin{array}{l}\text { Loteamentos e construções próximos ao } \\
\text { mar }\end{array}$ & 47,61 \\
\hline & Esportes aquáticos & 1,58 \\
\hline & Não opinaram & 4,78 \\
\hline & & Total 100 \\
\hline \multirow{4}{*}{ VISITANTE } & $\begin{array}{l}\text { Atividades agroextrativistas próximas } \\
\text { aos rios }\end{array}$ & 26,66 \\
\hline & $\begin{array}{l}\text { Loteamentos e construções próximos ao } \\
\text { mar }\end{array}$ & 53,33 \\
\hline & Não opinaram & 20,01 \\
\hline & & Total100 \\
\hline
\end{tabular}

Fonte: Organizado por Rocha, G. C.

Dados coletados em campanhas de campo, entre maio e junho de 2012.

Além das limitações, os entrevistados responderam ainda qual seria o maior problema ambiental da praia. Dessa forma, 52,5\% dos entrevistados disseram que os resíduos sólidos presentes na área se configuram como o problema ambiental mais sério do lugar. Essa realidade reafirma os problemas de infraestrutura higiênico-sanitária, como a coleta irregular do lixo e a falta de lixeiras, que potencializam os danos ambientais por efeito de contaminação e poluição, além de denunciar a necessidade de realizar projetos de educação ambiental com os populares.

Outros problemas também foram relatados, como a poluição sonora advinda de veículos automotores, especialmente nos períodos de alta-estação, citada por $16,6 \%$ das pessoas, e a erosão costeira, terceira resposta mais frequente, mencionada por $14,1 \%$ dos entrevistados. Um percentual de $10,1 \%$ dos entrevistados não opinou e 6,7\% apontou a presença de estruturas próximas ao mar.

Considerando-se a procedência dos entrevistados, observa-se que residentes e visitantes consideram o problema dos resíduos sólidos bastante relevante, sendo apontado por 55,55\% dos nativos e $40 \%$ dos visitantes, como se pode observar na tabela 6 . Outra observação interessante é que a erosão costeira não é mencionada pelo público visitante, sendo perceptível apenas pelo público que convive no local. 
Tabela 6 - Relação entre procedência e principais problemas ambientais

\begin{tabular}{c|c|c}
\hline \multirow{2}{*}{ PROCEDÊNCIA } & $\begin{array}{c}\text { PRINCIPAIS PROBLEMAS } \\
\text { AMBIENTAIS }\end{array}$ & $\%$ \\
\hline \multirow{4}{*}{ NATIVO } & Erosão & 17,46 \\
\cline { 2 - 3 } & Resíduos sólidos & 55,55 \\
\cline { 2 - 3 } & Poluição sonora & 17,46 \\
\cline { 2 - 3 } & Presença de estruturas próximas ao mar & 6,34 \\
\cline { 2 - 3 } & Não opinaram & 3,19 \\
\hline \multirow{5}{*}{ VISITANTE } & Resíduos sólidos & Total 100 \\
\hline \multirow{3}{*}{ Total } & Poluição sonora & 13,34 \\
\cline { 2 - 3 } & Presença de estruturas próximas ao mar & 6,66 \\
\cline { 2 - 3 } & Não opinaram & 40 \\
\hline \multirow{2}{*}{} & & Total 100 \\
\hline
\end{tabular}

Fonte: Organizado Rocha, G. C.

Dados coletados em campanhas de campo, entre maio e junho de 2012.

\section{CONSIDERAÇÕES FINAIS}

Com base nos resultados colhidos através dos questionários, pode-se concluir que as políticas de planejamento e gestão ambientais devem ser desenvolvidas especialmente para a conservação da paisagem natural costeira, a manutenção das taxas de visitação e o ordenamento da atividade turística, sobretudo o ecoturismo, além de incentivar a pequena pesca, o lazer e o veraneio.

Em relação à atividade turística, esta deve ser pensada de maneira a promover a inclusão de pequenos empreendedores, o que torna fundamental o desenvolvimento de estratégias de valorização dos produtos artesanais e da cultura local, além da organização dos envolvidos. Tal postura poderá garantir a geração de renda, mesmo em períodos de baixo fluxo de visitação, e promover a redução da pobreza através de um desenvolvimento menos excludente. Estas ações devem ser incorporadas às políticas nacionais de desenvolvimento da atividade turística e articuladas com as ações estaduais e municipais, possibilitando a descentralização dos recursos de fomento ao turismo, em especial no que se refere à infraestrutura.

No caso da infraestrutura, as deficiências higiênico-sanitárias referentes ao abastecimento de água, saneamento, coleta e destinação de resíduos sólidos, configuram-se, também, como fatores limitantes à atividade turística, além de configurarem-se como risco potencial à saúde de residentes e visitantes. Nesse sentido, são necessários investimentos voltados para a melhoria desses serviços. 
Para o desenvolvimento da pesca é importante estimular o associativismo comunitário entre os profissionais praticantes da pequena pesca, para fortalecer a categoria e buscar alternativas de valorização do pescado, como por exemplo, o beneficiamento dos produtos pesqueiros. Ações de financiamento voltadas para a modernização da atividade, especialmente da frota pesqueira, são igualmente necessárias. Ressalta-se que a exploração dos recursos biológicos carece de monitoramento intensivo, no intuito de evitar a sobrepesca e manter os estoques satisfatoriamente.

Além disso, fazem-se necessárias medidas de disciplinamento da ocupação que evitem a fixação de sedimentos das áreas mais dinâmicas da praia, a descaracterização da paisagem e o uso das APP's localizadas às margens dos cursos fluviais. No entanto, tais medidas não devem ser meramente proibitivas, nem tampouco culminarem com a expulsão das comunidades tradicionais do lugar, mas precisam ser acompanhadas de alternativas de renda para a população local. Ressalta-se, ainda, a importância de tais comunidades nos projetos de cunho conservacionista, haja vista o conhecimento que as mesmas possuem sobre as potencialidades naturais do lugar.

\section{REFERÊNCIAS}

AB'SABER, A. N. Fundamentos da geomorfologia costeira do Brasil atlântico inter e subtropical. Revista Brasileira de Geomorfologia, [s.1.], v. 1, n. 1, p. 27-43, 2000.

BRASIL. Resolução CIRM No 01, de 21 de novembro de 1990. Aprova o Plano Nacional de Gerenciamento Costeiro (PNGC). . Comissão Interministerial para Recursos do Mar, Brasilia, 1988. Disponível em: 〈www.ipef.br/legislacao/bdlegislacao/arquivos/17576.rtf>. Acesso em: 02 jun. 2014.

CAVALCANTI, A. P. B. Impactos e condições ambientais da zona costeira do estado do Piauí. 2000. 353 f. Tese (Doutorado em Geografia) - Instituto de Geociências e Ciências Exatas (IGCE), Universidade Estadual Paulista (UNESP), Rio Claro, 2000.

DIEGUES, A. C. S. O mito moderno da natureza intocada. 3. ed. Jaboticabal: Funep, 2006.

ERGIN, A. et al. A new methodology for evaluating coastal scenery: fuzzy logic systems. Area, [s.1.], v. 36, n. 4, p. 367- 386, 2004.

KOWARICK, L. Sobre a vulnerabilidade socioeconômica e civil Estados Unidos, França e Brasil. Revista Brasileira de Ciências Sociais - v. 18 n . 51, 2003.

LESSA, B. C.; POLETT, M. Preferências e percepção da paisagem na Ilha de Porto Belo, Santa Catarina, Brasil: uma contribuição a capacidade de carga turística. In: CONGRESSO LATINOAMERICANO DE CIÊNCIAS DO MAR, 12., 2007, Florianópolis. Anais..., Florianópolis: 2007. 
MARCELINO, R., L. Uma abordagem sócio-econômica e sócio-ambiental dos pescadores artesanais e outros usuários ribeirinhos do estuário do Rio Paraíba do Norte. Tropical Oceanografy, Recife, v. 33, n. 2, p. 179-192, 2005.

MATOS, M. P. A sensibilidade do lugar: um estudo de percepção ambiental na Ilha de Paquetá (RJ). 2010. 172 f. Tese (Doutorado em Geografia) -Universidade Estadual Paulista, Rio Claro, 2010.

MENDONÇA, F. A. Geografia socioambiental. Terra Livre, São Paulo, n. 16. p. 139-158, 2001.

MORAES, A. C. R. Contribuições para a gestão integrada da zona costeira do Brasil: elementos para uma geografia do litoral brasileiro. São Paulo: Hucitec/Edusp, 2007.

MORGAN, R. A novel, user-based rating sistem for tourist beaches. Pergamos, [s.1.], n. 20, p. 393410, 1999.

MUEHE, D. Critérios morfodinâmicos para o estabelecimento de limites da orla costeira para fins de gestão. Revista Brasileira de Geomorfologia, [s.1.], n.1, p. 35-44, 2001.

PEREIRA, L. C. C. et. al. The influence of the environmental status of Casa Caiada and Rio Doce beaches (NE - Brazil) on beaches users. Elsevier, [s.l.], v.46, p.1011-1030, 2003.

ROCHA, G. C.; DINIZ, M. T. M. Implicações da erosão costeira em atividades econômicas na praia da Caponga Cascavel - Ceará. Scientia Plena, [s.1.], v. 7, p. 1-9, 2011.

ROCHA, G. C.; DINIZ, M. T. M. Caracterização socioambiental da orla marítima da praia da Caponga litoral leste do estado do Ceará: subsídio ao gerenciamento costeiro. Scientia Plena, [s.l.], v. 10, p. 1-12, 2014.

ROCHA, G. C. Propostas para a elaboração de planos de gestão para a praia de Macapá - Luis Correia - Piauí . 2015. 213 f. Tese (Doutorado em Geografia) - Instituto de Geociências e Ciências Exatas, Universidade Estadual Paulista, Rio Claro, 2015.

ROCHA, G. C. Relação atmosfera e dinâmica sedimentar nas praias de Macapá e Maramar - Luis Correia - Piauí Brasil. CADERNO DE GEOGRAFIA (PUCMG. IMPRESSO), v. 26, p. 300-325, 2016.

SANTOS, I. R. et al. Influence of socio-economic characteristies of beach users on litter genetation. Elsevier, [s.1.], v. 48, p. 742-752, 2005.

STORI, F. T. et al. A importância da participação da população tradicional para a legitimidade da reserva extrativista do Corumbau (Bahia, Brasil). In: CONGRESSO LATINO-AMERICANO DE CIENCIAS DO MAR, 12. 2007, Florianópolis. Anais..., Florianópolis: COLACMAR, 2007.

TAVARES, A. C. et al. O assoreamento da represa dos sonhos na percepção dos moradores de Monte Aprazível (SP). Geografia, Rio Claro, v. 18, n. 2, p. 117-133, 1993. 
TUAN, YI-FU. Topofilia: um estudo da percepção, atitudes e valores do meio ambiente. São Paulo: Difel, 1980.

TUDOR, D. T.; WILLIANS, A. T. A rationale for beach section by the public on the coast of Wales, UK. Area, [s.1.], v. 38, n. 2, p. 153-164, 2006. 